\title{
Classical serological markers in pediatric inflammatory bowel disease in Brazil
}

\author{
Maraci RODRIGUES ${ }^{1}$, Cleonice BUENO² , Elizete Aparecida LOMAZI ${ }^{3}$, Maria Inez Machado FERNANDES ${ }^{4}$, \\ Clarice Blaj NEUFELD ${ }^{5}$, Maria Fernanda Marranghello D'AMICO ${ }^{6}$ and Fátima Regina De Almeida PATIÑ ${ }^{6}$
}

ABSTRACT - Background - Perinuclear anti-neutrophil cytoplasmic antibodies (p-ANCA) and anti-Saccharomyces cerevisiae antibodies (ASCAs) have long been used to differentiate between Crohn's disease (CD) and ulcerative colitis (UC), more recently having been used as prognostic indicators. Objective - To determine the diagnostic accuracy of serological markers in the identification of pediatric CD and UC in Sao Paulo, Brazil, as well as to correlate those markers with characteristics demographic and clinical of these two diseases. Methods - Retrospective cross-sectional multi-center study involving pediatric patients with inflammatory bowel disease (IBD). We identified ASCAs serological markers and p-ANCA, correlating their presence with demographic and clinical data, not only in the patients with IBD but also in a group of age-matched gastrointestinal disease-free controls. Results - A total of 122 patients, 74 with IBD ( $46 \%$ males), treated at four pediatric gastroenterology referral centers, the mean age of $13 \pm 7$ years, $49(66 \%)$ with CD, and $25(34 \%)$ with UC. The control Group comprised 48 patients ( $54 \%$ males). The proportion of patients testing positive for p-ANCA was significantly higher in the UC group (69.9\%) compared to the CD group (30.4\%), as well as being significantly higher in the CD group versus the control Group $(P<0.001$ for both). The proportion of patients testing positive for ASCA IgA (76.2\%) and ASCA IgG (94.4\%) markers was also significantly higher in the CD group than in the control Group $(P<0.001)$, and such positivity correlated significantly with the use of immunomodulatory medications such as azathioprine and anti-tumor necrosis factor agents (azathioprine 38.9\%, anti-TNF 55.6\%; $P=0.002$ ). In the $\mathrm{CD}$ group, the proportion of patients testing positive for the ASCA IgA was significantly higher among those who underwent surgery than among those who did not (26.86 $\pm 17.99 ; P=0.032$ ). Conclusion - In pediatric patients with IBD in Sao Paulo, Brazil, serological tests proving to be highly specific, although not very sensitive, for the diagnosis of IBD. However, the serological markers showed a positive correlation with the severity of the disease.

Keywords - Antibodies; antineutrophil cytoplasmic; antibodies; anti- Saccharomyces cerevisiae; inflammatory bowel disease.

\section{INTRODUCTION}

The diagnosis of pediatric inflammatory bowel disease (IBD) is always a challenge and is based on a combination of symptoms and signs at intestinal and extraintestinal sites, endoscopic findings in the upper and lower gastrointestinal tract, as well as radiological or capsule endoscopy findings consistent with the condition in the small bowel, assuming that other diseases with similar clinical manifestations have been excluded ${ }^{(1)}$. In approximately $25 \%$ of patients with IBD, the first symptoms appear before the age of $18^{(2)}$. Despite careful clinical evaluation, IBD-unclassified (IBD$\mathrm{U}$, a form of colonic IBD whose features make it impossible to define as either colitis of Crohn's disease or ulcerative colitis at diagnosis), seemed straightforward and whereas more than $14 \%$ are misdiagnosed with ulcerative colitis (UC), consequently undergoing unnecessary colectomy and ileoanal anastomosis ${ }^{(3)}$.

Classical serological markers, such as perinuclear anti-neutrophil cytoplasmic antibodies (p-ANCA) and anti-Saccharomyces cerevisiae antibodies (ASCAs), have been used in pediatric patients since 1993 and 1998, respectively ${ }^{(4,5)}$. Although they were initially used to differentiate between Crohn's disease (CD) and UC, later they have been used for predicting disease course and outcomes in IBD $^{(6-10)}$.

ANCAs are defined as autoantibodies directed against an unidentified component of the nuclear envelope within neutrophil granules. On indirect immunofluorescence (IIF), these antibodies present staining that is either cytoplasmic (c-ANCA) or perinuclear (p-ANCA); a further subtype comprises those that show the latter type of staining and are sensitive to deoxyribonuclease (DNase). High levels of such p-ANCA are more strongly associated with UC than with $\mathrm{CD}^{(6,11)}$.

Although it seems that ASCAs develop as an epiphenomenon during the onset of $\mathrm{CD}$, luminal antigens such as bacteria and fungus play essential roles in perpetuating the inflammatory process. In patients with $\mathrm{CD}$, the loss of immune tolerance in the presence of resident bacterial flora is one of the fundamental aspects of the pathogenesis of the disease ${ }^{(11)}$.

Given the severe clinical repercussions of IBD in children and adolescents, more efforts have been focused on improving the diagnosis and especially identifying patients at risk for a poor prognosis, including serological biomarkers ${ }^{(9,10)}$.

${ }^{1}$ Faculdade de Medicina da Universidade de São Paulo, Hospital das Clínicas, Departamento de Gastroenterologia, São Paulo, SP, Brasil. 2 Faculdade de Medicina da Universidade de São Paulo, Hospital das Clínicas, Laboratório de Investigação Médica Reumatologia, São Paulo, SP, Brasil. ${ }^{3}$ Universidade Estadual de Campinas, Hospital de Clínicas, Departamento de Pediatria, Campinas, SP, Brasil. ${ }^{4}$ Universidade de São Paulo, Faculdade de Medicina de Ribeirão Preto, Departamento de Pediatria, Ribeirão Preto, SP, Brasil. ${ }^{5}$ Santa Casa de São Paulo, Departamento de Pediatria, São Paulo, SP, Brasil. ${ }^{6}$ Complexo Hospitalar do Mandaqui, Unidade de Gastroenterologia Pediátrica, São Paulo, SP, Brasil.

Corresponding author: Maraci Rodrigues. E-mail: maraci@uol.com.br 
The lack of studies of the ASCA immunoglobulin (Ig)A, ASCA $\mathrm{IgG}$, and $\mathrm{p}$-ANCA serological markers in pediatric patients with IBD in Brazil motivated us to apply these markers with the following objectives: to determine the diagnostic accuracy of serological antibody tests for the identification of pediatric patients with $\mathrm{CD}$ or $\mathrm{UC}$, as well as to determine the prevalence of those serological markers in pediatric patients without gastrointestinal problems; and to correlate those markers with sex, age at symptom onset, age at diagnosis, time from symptom onset to diagnosis, site of the disease, type of treatment (clinical or surgical) and complications.

\section{METHODS}

A cross-sectional multi-center study involving children and adolescents with an established diagnosis of either DC or UC, based on the Porto criteria ${ }^{(1)}$. Children with atypical UC and IBD-U were excluded. We decided to publish this study which was done between 2005 and 2008 to determine the diagnostic accuracy of serological markers in the identification of pediatric CD and UC in four centers in São Paulo's state, Brazil Universidade de São Paulo Faculdade de Medicina Hospital das Clínicas, Departamento de Gastroenterologia e Laboratório de Investigação Médica (LIM) Reumatologia; Universidade Estadual de Campinas, Hospital de Clínicas, Departamento de Pediatria; Universidade de São Paulo, Faculdade de Medicina de Ribeirão Preto, Departamento de Pediatria; Santa Casa de São Paulo, Departamento de Pediatria Complexo Hospitalar do Mandaqui, Unidade de Gastroenterologia Pediátrica as well as to correlate those markers with characteristics demographic and clinical of the disease because this subject persists with great importance nowadays. Demographic and clinical data of the controls were obtained by reviewing their medical records.

Blood samples $(5 \mathrm{~mL})$ to test for ASCAs markers (IgA and $\mathrm{IgG}$ ) and p-ANCA were collected from patients and controls. We employed an indirect IIF technique to determine if the predominant staining pattern of the ANCAs was perinuclear ( $\mathrm{p}-\mathrm{ANCA}$ ) or cytoplasmic (c-ANCA), using human granulocytes fixed in ethanol and formalin as the standard method. The standard dilution of 1:20 was used, and the positive sera were titrated with antinuclear antibodies (ANAs) on human epithelial type 2 cells. Cases testing positive for c-ANCA were confirmed by fixation with an enzymelinked immunosorbent assay (ELISA) kit (INOVA Diagnostics, Inc., San Diego, CA, USA). Patients who were ANA positive were also $\mathrm{p}$-ANCA positive only if the $\mathrm{p}$-ANCA title was $>2$ dilutions greater than that of ANA. We also used ELISA (QUANTA Lite ASCA kit; INOVA Diagnostic Inc.) to quantify ASCAs. The pattern was arbitrarily designated negative: values from 0 to 20.0 IU/ $\mathrm{mL}$, indeterminate from 20.1 to $24.9 \mathrm{IU} / \mathrm{mL}$, and positive when above or equal to $25 \mathrm{IU} / \mathrm{mL}$. Positivity for ASCA IgG, ASCA IgA, or both were considered a marker for CD. Laboratory technicians were blinded for clinical histories and diagnosis.

The study was approved by the Research Ethics Committees of the respective centers. All participating patients gave written informed consent.

\section{Statistical analysis}

Chi-square tests of homogeneity or Fisher's exact tests were used to evaluate the association between serological markers and categorical variables. Mann-Whitney tests were used to determine the relation of markers and continuous variables. Mann-Whitney tests were used to evaluate the association between ASCAs markers and categorical variables or Kruskal-Wallis tests. Sensitivity and specificity values were calculated in comparison with the control Group. Statistical analyses were performed with the Statistical Package for the Social Sciences, version 13.0 (SPSS Inc., Chicago, IL, USA).

\section{RESULTS}

We evaluated 122 patients, 49 with a confirmed diagnosis of $\mathrm{CD}$, of whom 25 were male (CD group). In that group, ages $14 \pm 4.6$ years (range 1.6-18). We also evaluated 25 patients with a confirmed diagnosis of UC, 11 males (UC group). In the UC group, ages $12.5 \pm 4.8$ years (range 2-18). Also, we evaluated a group of 48 controls, ages $7.4 \pm 4.2$ years (range $0.5-18$ ), TABLE 1 .

The proportions of patients testing positive for $\mathrm{p}$-ANCA were significantly higher in the UC group $(69.6 \%)$ compared to the CD group $(30.4 \% ; P<0.001)$, as well as being significantly higher in the CD group than in the control Group $(0 \% ; P<0.001)$, TABLE 1 . TABLE 2 shows that the proportion of patients testing positive for the ASCA IgG marker was significantly higher in the CD group than in the control Group $(P<0.001)$ and that positivity for ASCA IgG correlated with the use of immunomodulatory medication (Azathioprine 38.9\%; anti-TNF 55.6\%; $P=0.002$ ). As shown in TABLE 3, the proportion of patients testing positive for the ASCA IgA marker was also significantly higher in the CD group $(76.2 \%)$ than in the control Group $(23.8 \% ; P=0.001)$.

There was no significant relationship between the detection of the serological markers and localization of the disease $(P>0.05$ for all), TABLES 1, 2, and 3 .

There was no significant relationship between the detection of the serological markers and the age-related measures $(P>0.05$ for all), TABLE 4. It is also noteworthy that the ASCA IgA marker values were statistically higher among individuals who had undergone surgery $(26.86 \pm 17.99 ; P=0.032)$, TABLES 5 and 6 .

p-ANCA marker is highly specific, albeit not sensitive, for the diagnosis of UC, TABLE 7. ASCAs IgG and IgA markers had high specificity and low sensitivity for the diagnosis of CD, TABLE 7.

Three patients in the UC group tested positive for c-ANCA, as confirmed by ELISA, which showed negativity for anti-myeloperoxidase antibodies and positivity for anti-proteinase three antibodies - $37 \mathrm{IU} / \mathrm{mL}, 32 \mathrm{IU} / \mathrm{mL}$, and $42 \mathrm{IU} / \mathrm{mL}$, respectively - well above the reference range of $\leq 25 \mathrm{IU} / \mathrm{mL}$.

\section{DISCUSSION}

The classic biomarkers p-ANCA and ASCA help in the differential diagnosis between pediatric $\mathrm{CD}$ and $\mathrm{UC}$, in the prognosis in $\mathrm{CD}$, in the clinical expression of $\mathrm{UC}$, and more recently its corrections with early treatment with anti-TNF, in addition to the association with the variability of the intestinal microbiome and the damage of the intestinal mucosa, justifying the interest in this subject in the present day ${ }^{(7-8,12-17)}$.

Limited data have been reported about serological biomarkers in pediatric IBD in the Brazilian population, but all of them including a cohort or case report in adult patients, except one study that included both adult and pediatric population ${ }^{(18-23)}$.

In the present study, the presence of p-ANCA was found to have a significant association with UC. Our study founded the accuracy of $\mathrm{p}$-ANCA testing for the detection of UC with a sensitivity of $64 \%$, specificity of $100 \%$, and negative predictive value of $84.2 \%$. 
TABLE 1. Characteristics of pediatrics patients, by the result of perinuclear anti-neutrophil cytoplasmic antibody testing.

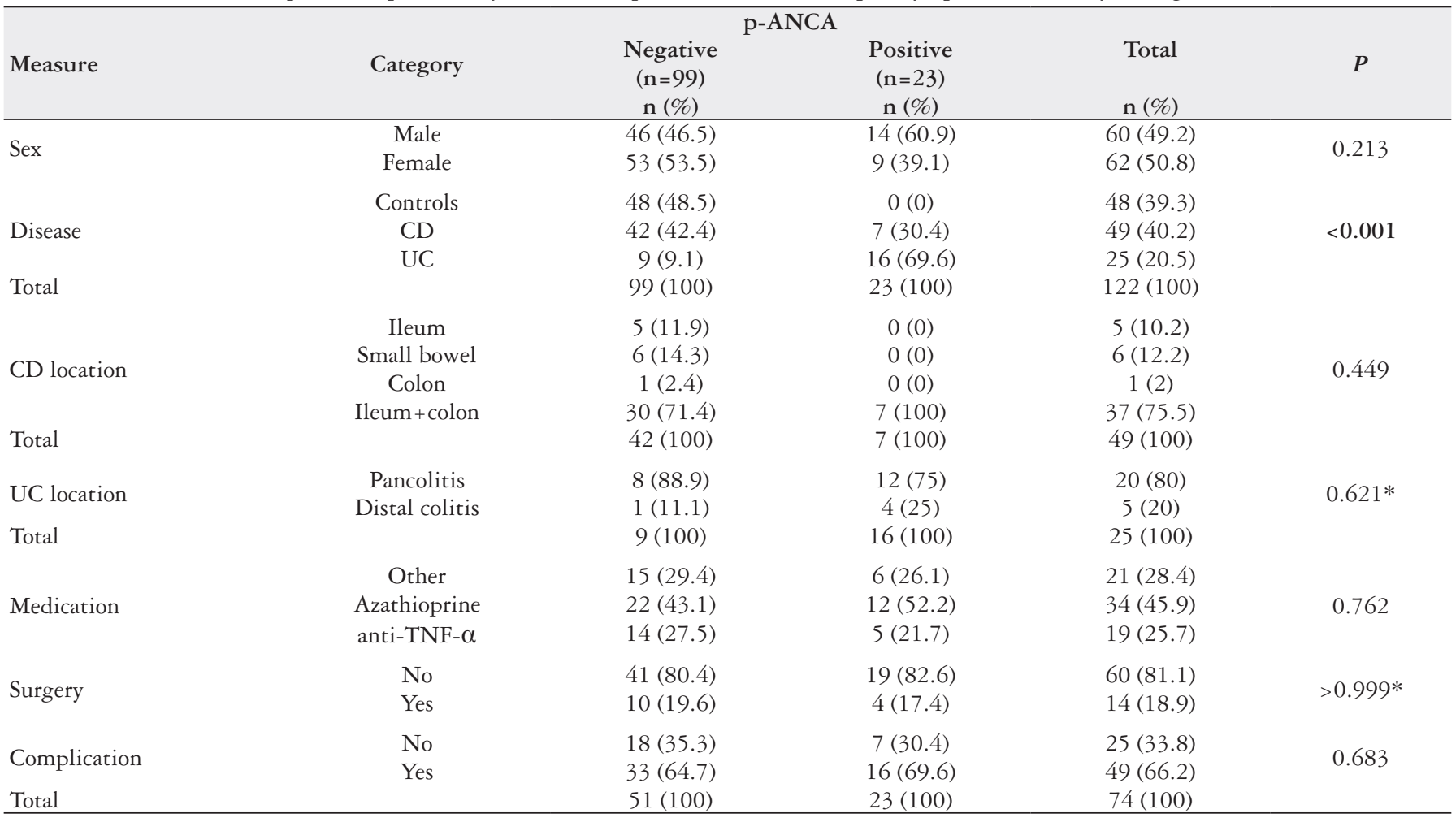

p-ANCA: perinuclear anti-neutrophil cytoplasmic antibody; anti-TNF- $\alpha$ : anti-tumor necrosis factor-alpha; CD: Crohn's disease; UC: ulcerative colitis. *Fisher's exact test.

TABLE 2. Characteristics of pediatrics patients, by the result of anti-Saccharomyces cerevisiae antibody immunoglobulin $G$ testing.

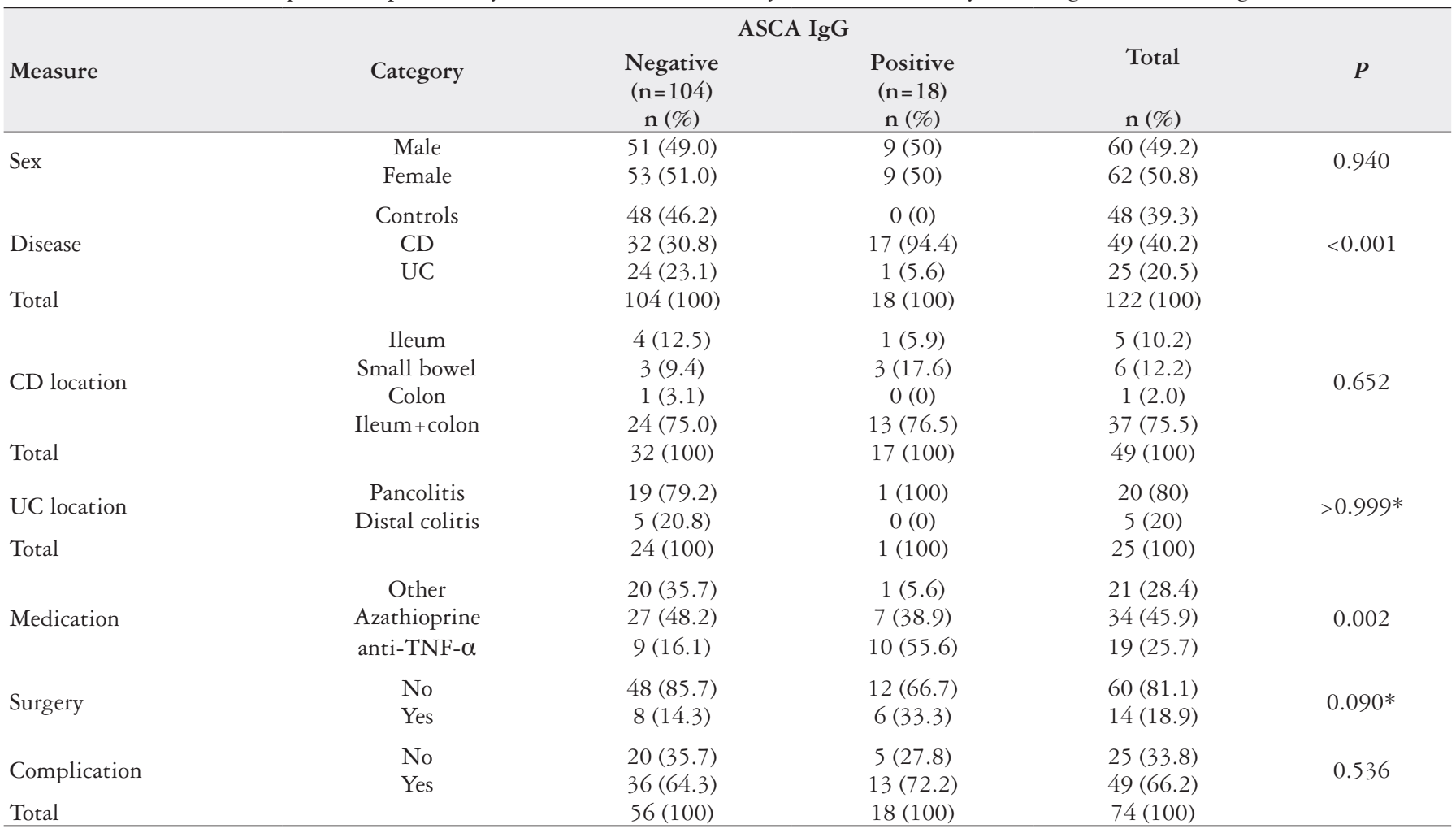

anti-TNF- $\alpha$ : anti-tumor necrosis factor-alpha; ASCA: anti-Saccharomyces cerevisiae antibody; CD: Crohn's disease; IBD: inflammatory bowel disease; IgG: immunoglobulin G; UC: ulcerative colitis. *Fisher's exact test. 
TABLE 3. Characteristics of pediatrics patients, by the result of anti-Saccharomyces cerevisiae antibody immunoglobulin A testing.

\begin{tabular}{|c|c|c|c|c|c|}
\hline & & & & & \\
\hline Measure & Category & $\begin{array}{c}\text { Negative } \\
(n=101)\end{array}$ & $\begin{array}{c}\text { Positive } \\
(n=21)\end{array}$ & Total & $P$ \\
\hline & & n $(\%)$ & n $(\%)$ & n $(\%)$ & \\
\hline Sex & Female & $50(49.5)$ & $12(57.1)$ & $62(50.8)$ & 0.524 \\
\hline & Controls & $43(42.6)$ & $5(23.8)$ & $48(39.3)$ & \\
\hline Total & & $101(100)$ & $21(100)$ & $122(100)$ & \\
\hline & Ileum & $4(12.1)$ & $1(6.3)$ & $5(10.2)$ & \\
\hline$C D$ lo & Small bowel & $4(12.1)$ & $2(12.5)$ & $6(12.2)$ & $0<00$ \\
\hline CD location & Colon & $0(0)$ & $1(6.3)$ & $1(2)$ & 0.488 \\
\hline UC location & Distal colitis & $5(20)$ & $0(0)$ & $5(20)$ & $\mathrm{N}-\mathrm{C}$ \\
\hline Total & & $25(100)$ & $0(100)$ & $25(100)$ & \\
\hline & Other & $19(32.8)$ & $2(12.5)$ & $21(28.4)$ & \\
\hline Medication & Azathioprine & $26(44.8)$ & $8(50)$ & $34(45.9)$ & 0.233 \\
\hline & anti-TNF- $\alpha$ & $13(22.4)$ & $6(37.5)$ & $19(25.7)$ & \\
\hline & No & $48(82.8)$ & $12(75)$ & $60(81.1)$ & \\
\hline Surgery & Yes & $10(17.2)$ & $4(25)$ & $14(18.9)$ & $0.486 *$ \\
\hline & No & $21(36.2)$ & $4(25)$ & $25(33.8)$ & 0 \\
\hline Complication & Yes & $37(63.8)$ & $12(75)$ & $49(66.2)$ & 0.401 \\
\hline Total & & $58(100)$ & $16(100)$ & $74(100)$ & \\
\hline
\end{tabular}

anti-TNF- $\alpha$ : anti-tumor necrosis factor-alpha; ASCA: anti-Saccharomyces cerevisiae antibody; CD: Crohn's disease; IBD: inflammatory bowel disease; IgA: immunoglobulin A; N-C: non-calculable; UC: ulcerative colitis. *Fisher's exact test.

TABLE 4. Comparison among serological markers, by age-related measures.

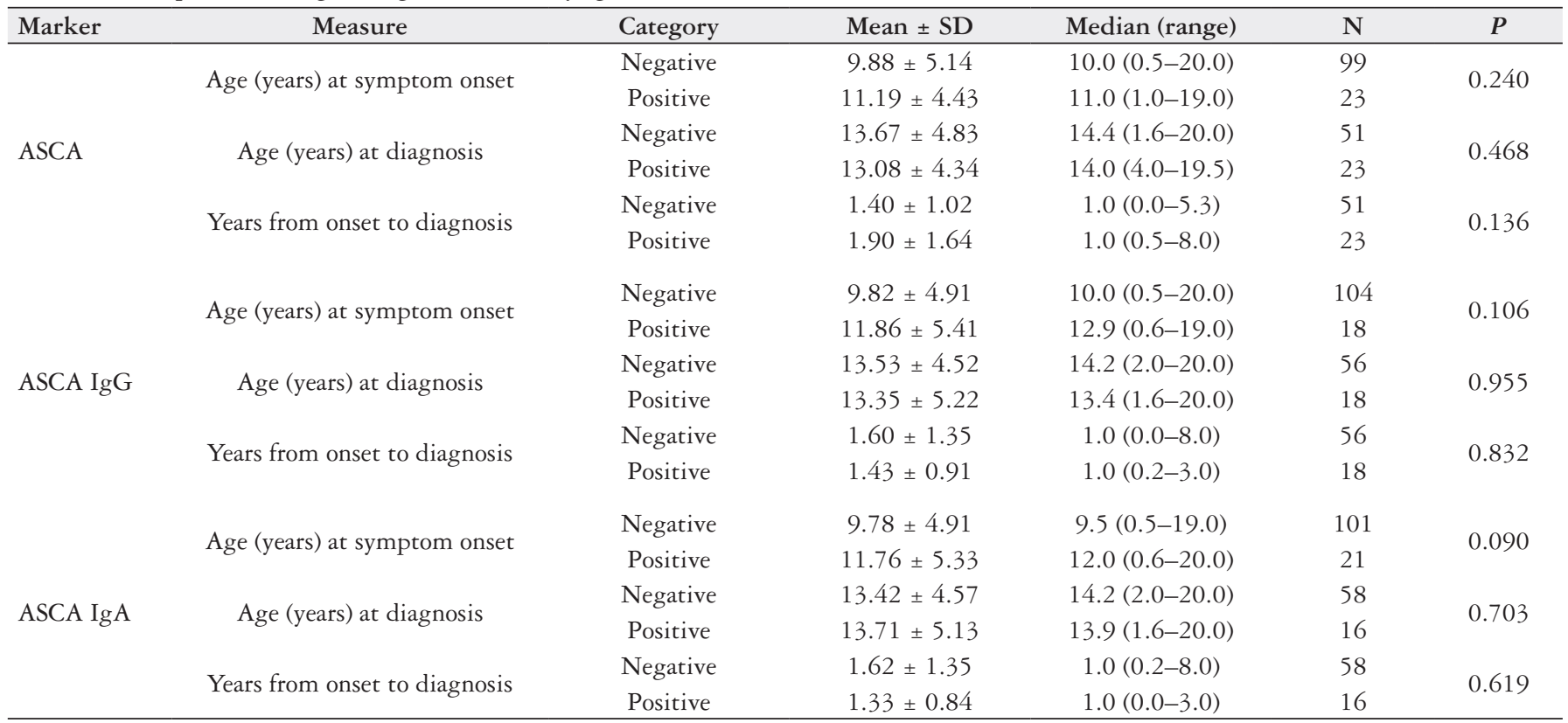

ASCA: anti-Saccharomyces cerevisiae antibody; IgA: immunoglobulin A; IgG: immunoglobulin G. 
TABLE 5. Characteristics of the anti-Saccharomyces cerevisiae antibody immunoglobulin G positive patients.

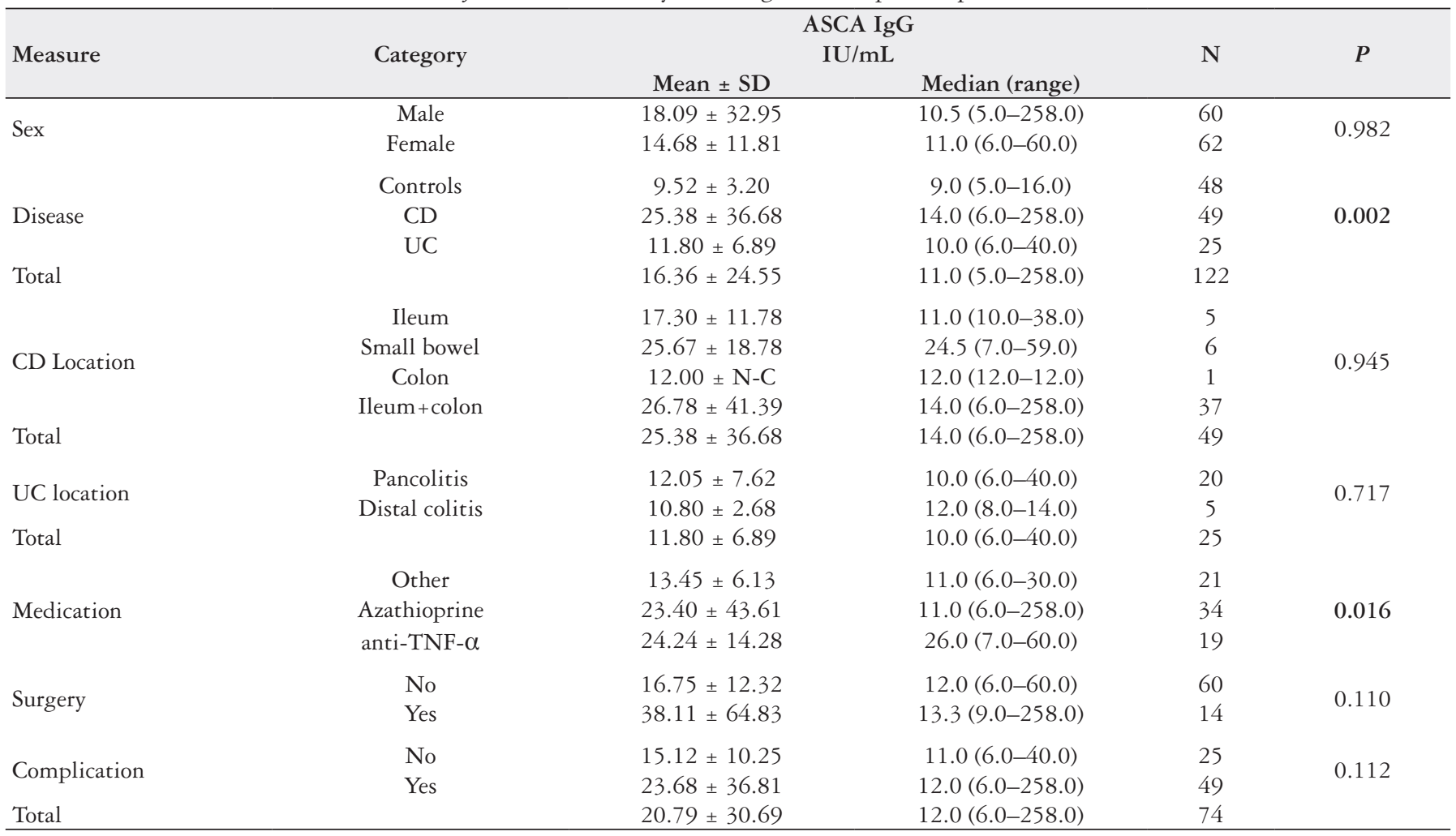

anti-TNF- $\alpha$ : anti-tumor necrosis factor-alpha; ASCA: anti-Saccharomyces cerevisiae antibody; CD: Crohn's disease; IgG: immunoglobulin G; N-C: non-calculable; UC: ulcerative colitis.

TABLE 6. Characteristics of the anti-Saccharomyces cerevisiae antibody immunoglobulin A-positive patients.

\begin{tabular}{|c|c|c|c|c|c|}
\hline \multirow{2}{*}{ Measure } & \multirow[b]{2}{*}{ Category } & \multicolumn{3}{|c|}{ ASCA IgA } & \multirow[b]{2}{*}{$P$} \\
\hline & & & & $\mathbf{N}$ & \\
\hline \multirow{2}{*}{ Sex } & Male & $16.28 \pm 16.21$ & $12.0(4.0-106.0)$ & 60 & 0.439 \\
\hline & Controls & $10.29 \pm 5.53$ & $8.0(4.0-28.0)$ & 48 & \multirow{3}{*}{0.001} \\
\hline \multirow[t]{2}{*}{ Disease } & CD & $30.58 \pm 33.78$ & $19.0(5.0-169.0)$ & 49 & \\
\hline & UC & $12.76 \pm 3.57$ & $12.0(6.0-21.0)$ & 25 & \\
\hline Total & Ileum & $29.00 \pm 30.33$ & $20.0(8.0-82.0)$ & 5 & \multirow{5}{*}{0.656} \\
\hline \multirow{3}{*}{ CD Location } & Small bowel & $44.33 \pm 62.26$ & $18.5(5.0-169.0)$ & 6 & \\
\hline & Colon & $53.00 \pm \mathrm{N}-\mathrm{C}$ & $53.0(53.0-53.0)$ & 1 & \\
\hline & Ileum + colon & $27.96 \pm 28.77$ & $17.0(7.0-150.0)$ & 37 & \\
\hline Total & & $30.58 \pm 33.78$ & $19.0(5.0-169.0)$ & 49 & \\
\hline Iocation UC & Pancolitis & $13.00 \pm 3.52$ & $12.5(9.0-21.0)$ & 20 & 0.717 \\
\hline \multirow[t]{2}{*}{ Medication } & Azathioprine & $28.03 \pm 32.20$ & $17.0(7.0-169.0)$ & 34 & \multirow[t]{2}{*}{0.017} \\
\hline & anti-TNF- $\alpha$ & $27.39 \pm 32.33$ & $15.0(5.0-150.0)$ & 19 & \\
\hline \multirow{2}{*}{ Surgery } & No & $24.03 \pm 30.81$ & $14.5(5.0-169.0)$ & 60 & \multirow{2}{*}{0.032} \\
\hline & Yes & $26.86 \pm 17.99$ & $21.5(11.0-68.0)$ & 14 & \\
\hline \multirow{2}{*}{ Complication } & No & $19.56 \pm 14.26$ & $15.0(6.0-54.0)$ & 25 & \multirow{3}{*}{0.433} \\
\hline & Yes & $27.11 \pm 33.69$ & $15.0(5.0-169.0)$ & 49 & \\
\hline Total & & $24.56 \pm 28.75$ & $15.0(5.0-169.0)$ & 74 & \\
\hline
\end{tabular}

anti-TNF- $\alpha$ : anti-tumor necrosis factor-alpha; ASCA: anti-Saccharomyces cerevisiae antibody; CD: Crohn's disease; IgA: immunoglobulin A; N-C: non-calculable; UC: ulcerative colitis. 
TABLE 7. Measures of the accuracy of ANCA) testing for the detection of ulcerative colitis, and ASCA IgA testing, and ASCA IgG testing for the detection of Crohn's disease.

\begin{tabular}{lcccc}
\hline & Sensitivity Estimate- 95\%CI & Specificity Estimate- 95\%CI & PPV Estimate - 95\%CI & NPV Estimate- 95\%CI \\
\hline ANCA & $64 \%(42.5-82 \%)$ & $100 \%(92.6-100 \%)$ & $100 \%(79.4-100 \%)$ & $84.2 \%(72.1-92.5 \%)$ \\
ASCA IgG & $34.7 \%(21.7-49.6 \%)$ & $100 \%(92.6-100 \%)$ & $100 \%(80.5-100 \%)$ & $60.0 \%(48.4-70.8 \%)$ \\
ASCA Ig A & $32.7 \%(20.0-47.5 \%)$ & $89.6 \%(77.3-96.5 \%)$ & $76.2 \%(52.8-91.8 \%)$ & $56.6 \%(44.7-67.9 \%)$ \\
\hline
\end{tabular}

IgA: immunoglobulin A; IgG: immunoglobulin G; PPV: positive predictive value; NPV: negative predictive value.

In pediatric IBD, sensitivity/specificity of p-ANCA in UC range between $28.9 \%$ to $83 \%$ and $65 \%$ to $94.2 \%$, respectively ${ }^{(6,12-15,18,24,25)}$.

Although p-ANCA was present in almost all our pediatric patients with UC, it was also positive around one-third of our CD patients as in others studies, and absent in all our control groups, in contrast with the results from others studies ${ }^{(6,12,14,20)}$.

Recently, one study evaluated the diagnostic utility of antineutrophil cytoplasmatic antibodies specific for proteinase-3 (PR3ANCA), a classical c-ANCA to distinguish pediatric UC from DC, and the authors founded similar results of sensitivity/specificity of this single marker as our study, but when they used a four antibodypanel including PR3-ANCA,X-ANCA (also called "atypical ANCA, with a rim-like perinuclear fluorescence), p-ANCA and ASCA IgG had an area under the ROC curve (AUC) of 0.90 in the training cohort and 0.84 in the external validation cohort for to distinguish between UC and CD, concluding is a superior and utilization of accessible panel can support accurate classification in the work-up of pediatric and adolescent patients with IBD patients ${ }^{(6)}$.

The interpreting and comparing $\mathrm{p}$-ANCA data between studies varying definitions and determination methods made direct comparison difficult. In some IBD studies, the expression "p-ANCA" has been synonymously used for atypical p-ANCA, in others, there is no differentiation between p-ANCA and atypical p-ANCA, and some author has been used the term X-ANCA only for the rim-like staining pattern, and interpreting it as the main ANCA found in UC patients when performing $\operatorname{IIF}^{(6,14)}$.

The other aspects we should take into consideration for these differences in the results ranges include an individual serological response to various microbial and autoantigens that can develop in IBD, the loss of mucosal immune tolerance, an increased mucosa permeability, influenced by several distinct genetic determinants and or environmental exposure across various geographic regions, age at diagnosis and the time of the sample at diagnosis or during the follow-up of the disease ${ }^{(12,26,27)}$.

We didn't found any correlation between p-ANCA and sex, the extension of the disease, or drugs using for his treatment as the same of other studies ${ }^{(12,14)}$.

Olbjorn et al. found in their study the majority of pediatric UC patients were ANCA positive and had extensive colitis as the usual phenotype in pediatric UC at diagnosis, like our study ${ }^{(14)}$. None of the UC patients received early TNF blocker treatment, but this could be due to TNF blocker therapy not being standard of care in pediatric UC patients during the period of study ${ }^{(14)}$.

It is important to remember that in our study we take the simple in the followed of the disease to measure the ANCA biomarker. Interestingly, Olbjorn et al. evaluated their pediatric population at diagnosis, e and 1-2 year later, and founded a decline in p-ANCA titles after treatment, in both $\mathrm{CD}$ and UC patients, and they concluded that p-ANCA status should probably be determined early in the disease course to be a prognostic factor ${ }^{(14)}$.

Spencer et al. examined disease phenotype and serology in a cohort of children newly diagnosed with UC, and they didn't find any correlation with the age of diagnosis or a specific phenotype through p-ANCA $\geq 100$ was strongly associated with pancolitis, like our study, but in our case no relationship with a higher level of $\mathrm{p}-\mathrm{ANCA}^{(15)}$.

Recently, Vojdani et al. assessed ASCA and ANCA-positive blood samples and measured antibodies against lipopolysaccharides (LPS) and barrier proteins (zonulin + occluding, S100B, and aquaporin-4) in these samples and compare them with the same antibodies in controls and they founded significant elevation in antibodies in about 30\% of ASCA-and ANCA-positive sera and demonstrate positive linear relationships between these antibodies. The findings suggest that individuals positive ASCA and ANCA have increased odds of developing intestinal and blood-brain barrier permeability compared to healthy subjects ${ }^{(28)}$.

In the present study, the presence of ASCA IgG and ASCA IgA was found to have a significant association with DC in our cohort. Our study founded the accuracy of ASCA IgG and ASCA IgA testing for the detection of CD the sensitivity of $34.7 \%$ and $32.7 \%$, the specificity of $100 \%$ and $89.6 \%$, and negative predictive value of $60 \%$ and $56.6 \%$ respectively. In pediatric IBD, sensitivity/ specificity of ASCA in CD range between $35 \%$ to $76 \%$ and $88 \%$ to $95 \%$, respectively ${ }^{(12,14,24-27)}$.

Our study didn't show a relationship signification between the age of diagnosis or localization and the presence of ASCA IgA or IgG. On the other hand, Markowitz et al. founded ASCA IgA and IgG in their patients less than $20 \%$ of those $0-7$ years compared to nearly $40 \%$ of those $8-15$ years $(P<0.001)$. By contrast, older age at diagnosis and small bowel $\mathrm{CD}$ independently increased the risk of ASCA IgA and IgG expression ${ }^{(27)}$.

Although ASCAs were present in our almost pediatric patients with DC, the studies showed this marker in $0 \%$ to $15 \%$ of UC and $0 \%$ to $5.8 \%$ of the control group ${ }^{(3,6,12,14)}$.

The appearance of these antibodies reflects a loss of tolerance to different intestinal bacteria. CD appears to rise from a dysregulated immune response to the endogenous enteric microflora in a genetically susceptible host. Defective innate immune responses, cause a cascade of events that ultimately are expressed as chronic intestinal inflammation ${ }^{(29)}$.

Some authors demonstrated that, in pediatric patients with $\mathrm{CD}$, ASCAs positivity correlated with an increased risk of intestinal resection. The detection of children with initial symptoms of CD could identify a risk group for surgery and the need for immunosuppressive therapy from the onset of the disease ${ }^{(8,16,30)}$. These findings agree with our study, in which most of the ASCAs-positive patients with CD had undergone surgery.

About the durability of this biomarker, Dubinsky and Seidman $^{(31)}$ reported the disappearance of ASCAs after surgery, in contrast with Kim et al. ${ }^{(17)}$ reported durability of the ASCA title over the time, at the diagnosis and the follow-up, the mean duration there was no significant difference in the title of ASCA before and after infliximab treatment. 
For to answer the doubt about the durability of this biomarker, we can observe what happened in the IBSEN study, which was investigated serological antibodies in a population-based inception cohort of $\mathrm{CD}$ had been followed prospectively for 20 years. No significant change of antibody status (positive versus negative) was found from 10-year to 20-year follow-up. Negative p-ANCA, positive ASCA IgA, and positive ASCA IgG at 10-year follow-up were all individuals associated with increased risk for CD-related surgery ${ }^{(8)}$.

Chandrakumar et al. showed that in comparison to ASCA IgG negative patients, ASCA IgG positive patients who were treated with biologics had a significantly lower relapse rate $^{(7)}$.

Kim et al. related that in patients who have not achieved mucosa healing, ASCA IgG is closely related to mucosal damage and clinical remission ${ }^{(17)}$.

Kansal et al. studied the variation of the gut mucosal microbiome with ASCA status in pediatric CD. They showed that ASCA-positive and ASCA-negative patients with CD have significant differences in gut microbiome composition, with could be influencing the phenotypes of the disease, especially the presence of Rhuminococcus torques and Yersinia enterocolitica ${ }^{(16)}$.

Haberman et al. studied a program involving eight macrophage and fibroblast activation genes, ASCA, and CBir1 biomarkers associated with risk of stenosis complication in children with pretreatment CD after 5 years of diagnosis ${ }^{(30)}$.

ASCA biomarker was evaluated in another gastrointestinal disease besides IBD. Kotze et al. ${ }^{(21)}$ evaluation of ASCA positivity in three cohorts of patients with $\mathrm{CD}$, celiac disease, and healthy individuals. The author founded that with statistical significance, ASCA IgA was positive in CD, celiac disease at diagnosis, and celiac disease with diet transgression, ASCA IgG in CD, and all groups with celiac disease. The authors suggested that the detection of ASCA is not a specific marker for Crohn's disease, but was associated with the inflammation of the small intestine. The increased levels of positive ASCA may be due to genetic factors and increased intestinal permeability ${ }^{(21)}$.

Grzybowska-Chlebowczyk et al. evaluation of frequency and title of IgA ASCA and IgG ASCA and p-ANCA, c-ANCA in children with IBD and occurrence of ASCA antibodies about the coexistence of food allergy (FA). They did not prove any relation between ASCA antibodies and the occurrence of food allergy in the examined groups of children ${ }^{(32)}$.

Other serological besides the classical biomarkers have been used in IBD patients. One study evaluated the predictive value of the Prometheus panel with seven IBD biomarkers, including classical markers (IBD serology seven; Prometheus Laboratories, San Diego, CA, USA) in children with suspected IBD ${ }^{(33)}$. The antiflagellin antibody, a new marker added to the panel, presented a sensitivity of $50 \%$ and a specificity of $53 \%$. Besides, the test was not reproducible in four of the ten patients evaluated. The authors concluded that, for IBD screening in pediatric patients, the IBD serology seven panel has a predictive value lower than that of the classic tests in pediatric IBD screening ${ }^{(33)}$.
Recently, the company introduced a new panel with 17 markers, with the addition of new serological markers of inflammation and genetic risk (IBD sgi Diagnostic; Prometheus Laboratories). For this new panel, an algorithm is used to arrive at a score for the diagnosis of IBD. However, an analysis of the efficacy of these results showed that, as the IBD serology seven panel, the results obtained with the IBD sgi panel were not statistically different from those obtained using only three classical markers ${ }^{(34)}$. Therefore, it is not clinically efficient or cost-effective.

\section{Strengths and limitations}

We acknowledge the small sample size as the main limitation of our study. Also, including patients with a different time lapse from diagnosis and serum sampling. Another strength is the employment of patients from four different centers.

Another aspect to be justified is that the period of data collection of the study was before the publication of the Modified Port Criteria, however, we emphasize that we did not include patients with atypical UC and IBD-U, not compromising the diagnostic criteria.

\section{CONCLUSION}

The results of the classical serological tests for IBD in children in Sao Paulo, Brazil were generally like those in the literature. We have demonstrated that such tests, although highly specific, are not sensitive and therefore do not facilitate the diagnosis. However, the results correlate positively with the severity of the disease, high ASCA IgA titles being seen in patients with CD and requiring treatment with azathioprine, anti-TNF- $\alpha$, or surgery.

\section{Authors' contribution}

Rodrigues $\mathrm{M}$ was the research adviser, wrote the manuscript, contributed to the study design, statistical analysis, interpretation of data and performed the critical review of the manuscript. Bueno $\mathrm{C}$ performed the laboratory tests and contributed to the study design. Lomazi EA collected the data, contributed to the study design and performed the critical review of the manuscript. Fermandes MIM collected the data and contributed to the study design. Neufeld CB collected the data and contributed to the study design. D'Amico MFM collected the data and contributed to the study design. Patiño FRA collected the data and contributed to the study design.

\section{Orcid}

Maraci Rodrigues: 0000-0002-1571-5282.

Cleonice Bueno: 0000-0003-3404-0572.

Elizete Aparecida Lomazi: 0000-0001-5504-4746.

Maria Inez Machado Fernandes: 0000-0002-0737-5062.

Clarice Blaj Neufeld: 0000-0003-1922-3143.

Maria Fernanda Marranghello D'Amico: 0000-0002-6133-0308. Fátima Regina De Almeida Patiño: 0000-0003-2439-3956. 
Rodrigues M, Bueno C, Lomazi EA, Fernandes MIM, Neufeld CB, D’Amico MFM, Patiño FRA. Marcadores sorológicos clássicos na doença inflamatória intestinal pediátrica no Brasil. Arq Gastroenterol. 2021;58(4):495-503.

RESUMO - Contexto - Os anticorpos citoplasmáticos anti-neutrófilos perinuclear (p-ANCA) e anticorpos anti-Saccharomyces cereviciae (ASCAs) são utilizados para diferenciar a doença de Crohn (DC) da colite ulcerativa (CU) e mais recentemente para correlacioná-los com o prognóstico da doença. Objetivo - 1) Determinar a acurácia diagnóstica dos marcadores sorológicos na identificação de DC e CU pediátrica em São Paulo, Brasil. 2) Correlacioná-los com as características demográficas e clínicas destas duas doenças. Métodos - Estudo multicêntrico transversal em pacientes com diagnóstico estabelecido de doença inflamatória intestinal (DII) determinando a presença dos marcadores sorológicos ASCAs e p-ANCA, correlacionando seus resultados com os dados demográficos e clínicos, e também em pacientes controles isentos de doenças gastrointestinal. Resultados - 122 pacientes, 74 com DII (46\% masculinos) em quatro centros de referência em Gastroenterologia Pediátrica, média de idade $13 \pm 7$ anos, 49 (66\%) com DC e 25 (34\%) com CU e 48 controles (54\% masculinos). O marcador p-ANCA apresenta maior porcentagem de detecção na CU (69,6\%), mas também na DC $(30,4 \%)$ quando comparado ao grupo controle $(P<0,001)$. Os marcadores ASCA $\operatorname{IgA}(76,2 \%)$ e $\operatorname{IgG}(94,4 \%)$ apresentam maiores porcentagens de detecção na DC, quando comparada ao controle $(P<0,001)$ e que a positividade do marcador esteve relacionada ao uso de medicações em pacientes portadores de DC que realizaram cirurgia $(26,86 \pm 17,99 ; P=0,032)$. Conclusão - Os resultados dos testes sorológicos em crianças com DII em São Paulo, Brasil, foram altamente específicos, mas pouco sensíveis para auxiliar no diagnóstico, embora com correlação positiva com a gravidade da doença.

Palavras-chave - Anticorpos citoplasmáticos; anti-neutrófilos; anticorpos; anti-Saccharomyces cerevisiae; doenças inflamatórias intestinais.

\section{REFERENCES}

1. IBD Working Group of the European Society for Paediatric Gastroenterology, Hepatology, and Nutrition (ESPGHAN). Inflammatory Bowel Disease in Children and Adolescents: Recommendations for Diagnosis - The Porto Criteria. J Pediatr Gastroenterol Nutr. 2005;41:1-7. doi: 10.1097/01.MPG.0000163736.30261.82.

2. Sýkora J, Pomahačová R, Kreslová M, Cvalínová D, Štych P, Schwarz J. Current global trends in the incidence of pediatric-onset inflammatory bowel disease. World J Gastroenterol. 2018,7;24:2741-63. doi:10.3748/ wjg. v24. i25.2741.

3. Birimberg-Schwartz L, Wilson DC, Kolho KL, Karolewska-Bochenek K, Afzal NA. Christine Spray C, et al. p-ANCA and ASCA in Children with IBD-Unclassified, Crohn's Colitis, and Ulcerative Colitis - A Longitudinal Report from the IBD Porto Group of ESPGHAN. Inflamm Bowel Dis. 2016;22:1908-14. doi: 10.1097/MIB.0000000000000784.

4. Proujansky R, Fawcett PT, Gibney KM, Treem W.R, Hyams JS. Examination of anti-neutrophil cytoplasmic antibodies in childhood inflammatory bowel disease. J Pediatr Gastroenterol Nutr. 1993;17:193-97. doi: 10.1097/00005176-19930800000011.

5. Ruemmele FM, Targan SR, Levy G, Dubinsky M, Braun J, Seidman EG. Diagnostic accuracy of serological assays in pediatric inflammatory bowel disease. Gastroenterology. 1998;115:822-29. doi: 10.1016/s0016-5085(98)70252-5.

6. Hom MP, Peter AM, Grunder FR, Leichtle AB, Spalinder J, Schibli S, et al PR3-ANCA and panel diagnostics in pediatric inflammatory bowel disease to distinguish ulcerative colitis from Crohn's disease. Plos One. 2018;13: e0208974 doi.org/10.1371/journal.pone.0208974.

7. Chandrakumar A, Georgy M, Agarwal P, j'Jong G, El-Matary W. Anti-Saccharomyces cerevisiae antibodies as a prognostic biomarker in children with Crohn's disease. J Pediatr Gastroenterol Nutr. 2019;69:82-7.doi: 10.1097/ MPG.0000000000002311.

8. Kristensen VA, Cvancarova M, Hoivik ML, Moum B, Vatn MH. Serological antibodies and surgery in a population-based inception cohort of Crohn's disease patients - the IBSEN study. Scand J Gastroenterol. 2020,55:436-41. doi:10.108 0/00365521.2020.1745879.

9. Ricciuto A, Aardoom M, Orlanski-Meyer E, Navon D, Carman N, Aloi M, et al. Predicting Outcomes in Pediatric Crohn's Disease for Management Optimization: Systemic Review and Consensus Statements From the Pediatric Inflammatory Bowel Disease - Ahead Program. Gastroenterology. 2021;160:403-36. doi:10.1053/j.gastro.2020.07.065.

10. Orlansky-Meyer E, Aardoon M, Ricciuto A, Navon D, Carman N, Aloi M, et al. Predicting Outcomes in Pediatric Ulcerative Colitis for Management Optimization: Systematic Review and Consensus Statements From the Pediatric Inflammatory Bowel Disease. Gastroenterology. 2021;160:378-402. doi:10.1053/j. gastro.2020.07.066.

11. Dotan I. New Serologic Markers for Inflammatory Bowel Disease Diagnosis. Dig Dis. 2010;28:418-23. doi:10.1159/000320396.

12. Saadah OI, Al-Mughales JA. Serological markers of inflammatory bowel disease in children from the Western region of Saudi Arabia. Arab J Gastroenterol. 2013;14:78-82. doi: 10.1016/j.ajg.2013.05.004
13. Kovács M, Müller KE, Papp M, Lakatos PL, Csöndes M, Veres G. New serological markers in pediatric patients with inflammatory bowel disease. World J Gastroenterol. 2014;20:4873-82. doi: 10.3748/wjg.v20.i17.4873

14. Olbjørn C, Milada Småstuen MC, Thiis-Evensen E, Nakstad B, Vatn MH, Perminow G. Serological markers in the diagnosis of pediatric inflammatory bowe disease and as predictors for early tumor necrosis factor blocker therapy. Scand J Gastroenterol. 2017;52:414-9. doi:10.1080/00365521.2016.1259653.

15. Spencer EA, Davis SM, Mack DR, Boyle BM, Griffiths AM, LeLeiko NS, et al Serologic Reactivity Reflects Clinical Expression of Ulcerative Colitis in Children. Inflamm Bowel Dis. 2018;24:1335-43. doi:10.1093/ibd/izy009.

16. Kansal S, Catto-Smith AG, Boniface K, Thomas S, Cameron DJ, Oliver M, et al. Variation of Gut Mucosal Microbiome with Anti-Saccharomyces cerevisiae Antibody Status in Pediatric Crohn Disease. J Pediatr Gastroenterol Nut. 2019;69:696-703. doi:10.1097/MPG.0000000000002461.

17. Kim MJ, Kim E, Kang B, Lee Y, Kang ES, Choe YH. Anti- Saccharomyces cerevisiae Antibody in Pediatric Crohn's Disease Patients without Mucosal Healing Is a Useful Marker of Mucosal Damage. Gut Live. 2020;30:1-8. doi: 10.5009/ gnl20212.

18. Steinwurtz F, Scheinberg M. Serologic diagnosis of inflammatory bowel disease (ASCA and ASCA): Evaluation of 70 cases. GED. 2001;20:41-42.

19. Cabral VL, Misputen SJ, Catapani WR. Anti-neutrophil cytoplasmatic antibodies in Brazilian patients with inflammatory bowel disease. Hepatogastroenterology. 2003;50:412-5.

20. Nisihara RM, Carvalho WB, Utiyama SRR, Amarante H, Baptista ML. Diagnostic Role and Clinical Association of ASCA and ANCA in Brazilian Patients with Inflammatory Bowel Disease. Dig Dis Sci. 2010;55:2309-15. doi:10.1007/ s10620-009-0998-7.

21. Kotze LMS, Nisihara RM, Utiyama SRR, Kotze PG, Theiss PM, Olandoski M. Antibodies Anti-Saccharomyces Cerevisiae do not Differentiate Crohn's Disease from Celiac Disease. Arq Gastroenterol. 2010;47:242-5. doi.org/10.1590/S000428032010000300006

22. Santos CE, Dal Pizzol VI, Aragão SC, Rachid Filho A, Marques FM. C-ANCA-associated vasculitis in patients with ulcerative colitis: a case report. Rev Bras Reumatol. 2013;53:441-3.

23. Duarte-Silva M, Afonso PC, Souza PR, Peghini BC, Rodrigues-Junior V, Cardoso CRB. Reappraisal of antibodies Against Saccharomyces cerevisiae (ASCA) as persistent biomarkers in quiescent Crohn's disease. Autoimmunity. 2019;52:37-47. doi:10.1080/08916934.2019.1588889.

24. Zhouludev A. Serologic testing with ANCA, ASCA, and Anti-OmpC in children and Young adults with Crohn's disease and ulcerative colitis: diagnostic value and correlation with disease phenotype. Am. J. Gastroenterol. 2004;99:2235-41. doi: 10.1111/j.1572-0241.2004.40369.x.

25. Khan K, Schwarzenberg SJ, Sharp H, Greenwood D, Weisdorf-Schindele S. Role of serology and routine laboratory in childhood inflammatory bowel disease. Inflamm Bowel Dis. 2002;8:325-29. doi: 10.1097/00054725-20020900000003. 
26. Ashorn S, Honkanen T, Kolho KL, Ashorn M, Valineva T, Wei B, et al. Fecal Calprotectin levels and Serological Responses to Microbial Antigens among Children and Adolescents with Inflammatory Bowel Disease. Inflamm Bowel Dis. 2009;15:199-205. doi:10.1002/ibd.20535.

27. Markowitz J, Kugathasan S, Dubinsky M, Mei L, Crandall W, Leleiko N, et al. Age of Diagnosis Influences Serologic Responses in Children with Crohn Disease: A Possible Clue to Etiology? Inflamm Bowel Dis. 2009;15:714-9. doi:10.1002/ ibd.20831.

28. Vojdani A, Vojdani E, Herbert M, Kharrazian D. Correlation between Antibodies to Bacterial Lipopolysaccharides and Barrier Protein in Sera Positive for ASCA and ANCA. Int J Mol Sci. 2020;21:1381. doi:10.3390/ijms21041381.

29. Strober W, Fuss I, Mannon P. The fundamental basis of inflammatory bowel disease. J Clin Invest. 2007;117:514-21. doi: 10.1172/JCI30587.

30. Haberman Y, Minar P, Karns R, Dexheimer PJ, Ghandikota S, Tegge S, et al. Mucosal inflammatory and Wound Healing Gene Programs Reveal Targets for Structuring Behavior in Pediatric Crohn's Disease. J Crohns Colitis. 2020;15:27386. doi:10.1093/ecco-jec/jjaa166.
31. Dubinsky MC, Seidman EG. Diagnostic markers of inflammatory bowel disease. Curr Opin Gastroenterol. 2000;16:337-42. doi:10.1097/00001574-20000700000008.

32. Grzybowska-Chlebowczyk U, Wos H, Sieron AI, Wiecek S, Augusciak-Duma A, Koryciak-Komarska H, et al. Serologic Investigation in Children with Inflammatory Bowel Disease and Food Allergy. Mediators Inflamm. 2009;2009:512695. doi:10.1155/2009/512695.

33. Benor S, Russell GH, Silver M, Israel EJ, Yuan Q, Winter HS. Shortcomings of the inflammatory bowel disease Serology 7 panel. Pediatrics. 2010;125:1230-6. doi: 10.1542/peds.2009-1936.

34. Shirts B, von Roon AC, Tebo AE. The entire predictive value of the Prometheus IBD sgi diagnostic product may be due to the three least expensive and most available components. Am J Gastroenterol. 2012;107:1760-1. doi: 10.1038/ ajg.2012.238. 